\title{
The effect of pain severity on balance, postural stability and fall risk in patients with shoulder pathologies
}

\author{
Yonca Eker ${ }^{1}$, Beliz Belgen Kaygısız
}

\author{
${ }^{1}$ Physiotherapy Unit, Dr. Burhan Nalbantoğlu State Hospital, Nicosia, Northern Cyprus, \\ Mersin, Turkey \\ 2European University of Lefke, Faculty of Health Sciences, Department of \\ Physiotherapy and Rehabilitation, Lefke, Northern Cyprus, Mersin, Turkey
}

Submitted: 28 January 2020; Accepted: 5 March 2020;

Online publication: 19 April 2020

Arch Med Sci 2021; 17 (2): 390-396

DOI: https://doi.org/10.5114/aoms.2020.94491

Copyright $\odot 2020$ Termedia \& Banach

\section{Abstract}

Introduction: The study aimed to investigate how pain severity in the shoulder region affects balance ability, postural stability and fall risk.

Material and methods: Sixty participants with shoulder pain, aged 42.45 \pm 6.51 years, were assessed using a Visual Analog Scale (VAS); they were divided into 2 subgroups as a mild pain group (group 1) and a moderate/ severe pain group (group 2). According to VAS-at rest the mild-pain group included 39 and the moderate/severe-pain group included 21 subjects. According to VAS-during movement, the mild-pain group included 19 and the moderate/severe-pain group included 41 subjects. Balance ability-postural stability, fall risk and fear of falling were assessed by the Sportkat System, Berg Balance Scale (BBS), and Fall Efficacy scale (FES) respectively. Differences of variables between mild pain and moderate/severe pain groups were analyzed by the independent groups $t$-test in groups conforming to a normal distribution and the Mann-Whitney $U$ test for the variables that did not fit a normal distribution.

Results: A positive relationship was found between VAS-at rest and double-foot static balance test score right-left $(\mathrm{RL})$ ratio, while a negative relationship was found between VAS-at rest and BBS score $(p<0.05)$. Significant differences were found between right foot static balance left score and $\mathrm{RL}$ ratio according to pain at rest $(p<0.05)$.

Conclusions: The results indicated that shoulder pain severity affects balance parameters. As pain level at rest increases, postural sway increases in a medio-lateral direction, and towards the left while standing on the right foot. Approaches regarding increasing balance and postural instability should be included in physiotherapy and rehabilitation programs of patients with shoulder pain at an early phase to protect patients from balance problems and fall risk.

Key words: shoulder, pain, balance, postural stability, fall risk.

\section{Introduction}

The most common symptom after back and neck pain among musculoskeletal pathologies is shoulder pain [1, 2]. One in three adults experiences shoulder pain [1,2] and limitation in shoulder movements [2]. Prevalence of shoulder pain caused by musculoskeletal pathologies is

\author{
Corresponding author: \\ Assist. Prof. Beliz Belgen \\ Kaygisiz \\ European University of Lefke \\ Faculty of Health Sciences \\ Department of \\ Physiotherapy and \\ Rehabilitation \\ Lefke, Northern Cyprus \\ TR-10, Mersin, Turkey \\ E-mail: bkaygisiz@eul.edu.tr
}


high in the working-age population $[1,2]$ and it affects functions related to work as well as the use of leisure-time activities [2]. Also, complaints of shoulder pain increase with age [1, 2].

Pain following injury is a result of the activation of the nociceptive system, which is a part of the somatosensory system [3]. Sensory information provided from the shoulder (proprioception) comes to the central nervous system (CNS), where information is associated with other parts of the nervous system and CNS transforms this knowledge into an efferent motor response for coordinated motion patterns and functional stability (neuromuscular control) [4].

Patients with shoulder pain have been proven to have a deficit in shoulder proprioception [5] and deficiencies in the trunk and lower extremity coordination as well $[5,6]$. Somatosensory deficits in the body, such as the lower extremities or trunk, can cause general functional limitations in the shoulder region $[5,6]$.

Disorder of one or more sensory inputs coming through afferent ways from the visual, somatosensory, or vestibular system $[7,8]$ causes impaired balance control and falls [8-10]. As pain affects the somatosensory system [3], this causes decreased balance ability [3, 5]. Also, balance control and muscle inhibition pathways caused by pain share some pathways in the CNS $[3,5]$. Therefore, muscle inhibition mechanisms caused by pain can adversely affect balance ability [5, 11]. Pain increases pre-synaptic inhibition of muscle afferents and affects the central modulation of the proprioceptive spindles of muscles $[5,11$, 12]. These changes decrease muscle control and increase postural sway [11]. A recent study in which patients with shoulder pain were compared with healthy subjects showed that pain may also negatively affect balance by disrupting neural rate processing [5].

Decreased balance can lead to mobility limitations, falls and disabilities [13]. Falls may lead to permanent and critical consequences such as injury, long-term disability, decreased activity and mobility, and fear of falling $[8,14,15]$. There is a need for postural stability (static and dynamic balance) during the performance of daily living activities [9]. Falling and loss of balance occur more frequently in tasks related to movement, and less frequently in static activities [9]. In relation to impaired balance, chronic musculoskeletal pain is associated with an increased risk of falls [13, 16], which decreases the level of physical activity [16]. Fear of falling is a worrying result of the falls $[14,15,17]$. Fear results in the deterioration of the ability of movement without falling as well as the avoidance of activity, reduced mobility, social isolation and reduced quality of life $[8,14,15,18]$.
Literature studies have shown results such as age being associated with the risk of falls, pain in the musculoskeletal system and falls and also a relationship between pain and balance is shown [9, 13-15, 19]. Falls are a great concern for most patient groups, including even patients with respiratory problems, who also experience pain and musculoskeletal disorders which results in increased fall risk [20, 21]. However, there is little published research investigating the relationship between different levels of shoulder pain, balance ability, falling risk and fear of falling, involving all age groups diagnosed with musculoskeletal shoulder problem. Although it is shown that the balance of patients with shoulder pain has been negatively affected, it is unclear how the level of pain affects balance parameters. Therefore, in this study, we aimed to investigate the relationship between the severity of pain, balance and postural stability, as well as fall risk in mainly shoulder pathologies. We hypothesized that when people who have pain in the shoulder due to shoulder pathology are grouped according to their pain severity, as the pain severity increases, the balance ability, postural sway and falling risk will be affected in a negative way.

\section{Material and methods}

Patients who applied to the a private physiotherapy and rehabilitation center between March 2018 and May 2018 for physiotherapy treatment and who had a diagnosis of shoulder pathology were included. Inclusion criteria were having a shoulder pathology, being between the ages of 18 and 50 and the presence of shoulder pain for 3 months or longer. Presence of injury in lower extremities during the last 6 months affecting functional capacity, presence of a history of reconstruction surgery on the shoulder or lower extremity (e.g. arthroscopic rotator cuff repair, knee prosthesis, cruciate ligament plastic surgery), presence of acute or chronic pain (including muscular pain) originating from the vertebral column or lower extremities, presence of any neurological disease or chronic headache, presence of inner ear disease, acute dizziness, presence of vision or hearing impairment to prevent testing, psychiatric illness and psychiatric drug use, drug use affecting the central nervous system and the failure to complete specified tests were determined as exclusion criteria. After the method of the study had been structured, $G^{*}$ Power software 3.1.9.2 was used to set the sample size. For a 0.5 effect size with 0.95 power, a total of 48 participants were needed.

Seventy-one people who met the inclusion criteria were invited to participate. Seven of these individuals refused to participate. Four people were excluded, as two suffered ankle pain, one had knee pain and one was using depression 
medication. As a result, the study was completed with 60 people. All individuals were informed in detail about the study and an informed consent form was signed. Ethical approval for this study was obtained from ethics committee at European University of Lefke (ÜEK/03/02/04/1617/7).

Individuals' physical-social demographic information was first recorded by the investigator physiotherapist through a face-to-face interview. Pain at rest and pain with movement were assessed on a one-to-one basis according to the Visual Analog Scale (VAS) [22]. According to the VAS, values of 0-3 were considered as mild pain, values of 4-6 as moderate pain and values of $7-10$ as severe pain. Individuals were divided into two groups as mild pain group (group 1) and moderate/severe pain group (group 2). According to VAS-at rest group 1 included 39 and group 2 included 21 subjects and according to VAS-during movement group 1 included 19 and group 2 included 41 subjects.

Static-dynamic balances and postural sway of individuals were evaluated objectively with the Sportkat System (Computerized Kinesthetic Ability Trainer, Sportkat model 4000-TS), which is validated to objectively assess static and dynamic balance [7]. Individuals were assessed for static balance, in the form of a double leg and a right/left one foot standing when arms cross over on the chest. The investigator required individuals to hold the red indicator in the middle of the screen for $30 \mathrm{~s}$. Dynamic balance was assessed by asking individuals to follow the moving indicator on the screen for $30 \mathrm{~s}$ while they were standing on two platforms.

The Berg Balance Scale was used to assess the participant's ability to balance and fall risk during 14 different tasks $[23,24]$. This tool is a reliable and valid tool and is widely used for different diagnoses [23, 24]. The Falls Efficacy Scale is a valid tool [25] which is used to assess the level of concern about falling during 16 different activities inside and outside the home. All evaluations were completed within 40-60 min with the necessary rest periods in between.

\section{Statistical analysis}

Descriptive statistics were used to give information about the general characteristics of cases. Relationships between variables were examined using Spearman correlation. Differences of variables between the mild pain and moderate/severe pain groups were analyzed by the independent groups $t$-test in the groups conforming to a normal distribution and the Mann-Whitney $U$ test for the variables that did not fit the normal distribution. Compliance of the variables with a normal distribution was checked by the Shapiro-Wilks test. The significance level was set at $p<0.05$.

\section{Results}

The average age of the participants in the study was $42.45 \pm 6.51$ years, average height

Table I. Demographic and medical characteristics of participants

\begin{tabular}{|c|c|c|c|c|c|}
\hline \multirow[t]{2}{*}{ Parameter } & \multicolumn{2}{|c|}{ VAS- at rest $(n=60)$} & \multicolumn{2}{|c|}{ VAS-during movement $(n=60)$} & \multirow[t]{2}{*}{$P$-value } \\
\hline & $\begin{array}{l}\text { Group } 1 \\
(n=39)\end{array}$ & $\begin{array}{l}\text { Group } 2 \\
(n=21)\end{array}$ & $\begin{array}{l}\text { Group } 1 \\
(n=19)\end{array}$ & $\begin{array}{l}\text { Group } 2 \\
(n=41)\end{array}$ & \\
\hline Age [years] & $41.44 \pm 7.47$ & $44.33 \pm 3.65$ & $42.58 \pm 6.93$ & $42.39 \pm 6.39$ & 0.36 \\
\hline Women & 24 & 13 & 12 & 25 & \\
\hline Men & 15 & 8 & 7 & 16 & \\
\hline Body weight [kg] & $\begin{array}{r}75.50 \\
\pm 15.52\end{array}$ & $\begin{array}{c}73.54 \\
\pm 12.81\end{array}$ & $\begin{array}{r}73.65 \\
\pm 15.47\end{array}$ & $75.35 \pm 14.27$ & 0.71 \\
\hline Body height [m] & $1.67 \pm 0.08$ & $1.64 \pm 0.08$ & $1.66 \pm 0.08$ & $1.66 \pm 0.08$ & 0.12 \\
\hline BMI $\left[\mathrm{kg} / \mathrm{m}^{2}\right]$ & $26.64 \pm 4.73$ & $27.41 \pm 5.61$ & $26.12 \pm 5.11$ & $27.28 \pm 5$ & 0.69 \\
\hline Dominant arm & $35 \mathrm{R} / 4 \mathrm{~L}$ & $20 \mathrm{R} / \mathrm{L}$ & $16 \mathrm{R} / 3 \mathrm{~L}$ & $39 \mathrm{R} / 2 \mathrm{~L}$ & \\
\hline Dominant leg & $38 \mathrm{R} / 1 \mathrm{~L}$ & $20 \mathrm{R} / 1 \mathrm{~L}$ & $18 \mathrm{R} / 1 \mathrm{~L}$ & $40 \mathrm{R} / 1 \mathrm{~L}$ & \\
\hline Affected shoulder & $18 \mathrm{R} / 21 \mathrm{~L}$ & $12 \mathrm{R} / 9 \mathrm{~L}$ & $6 \mathrm{R} / 13 \mathrm{~L}$ & $24 \mathrm{R} / 17 \mathrm{~L}$ & \\
\hline Affected arm when dominant (\%) & 46.15 & 61.90 & 47.36 & 63.41 & \\
\hline Pain severity $0-3$ VAS & 39 & - & 19 & - & \\
\hline Pain severity $4-10$ VAS & - & 21 & - & 41 & \\
\hline Pain duration 6 months $\geq{ }^{*} \geq 3$ months & 9 & 7 & 8 & 12 & \\
\hline Pain duration $>6$ months & 30 & 14 & 11 & 29 & \\
\hline
\end{tabular}


$1.66 \pm 0.08 \mathrm{~m}$, body weight $74.81 \pm 14.55 \mathrm{~kg}$ and body mass index (BMI) $26.91 \pm 5.02 \mathrm{~kg} / \mathrm{m}^{2}$. No statistically significant differences were found between the descriptive statistics of subjects. Demographic and medical characteristics of the subjects participating in the study are shown in Table I.
Of the 60 participants in our study, 38 (63.3\%) had impingement syndrome, 11 (18.3\%) had calcified tendinitis, $4(6.7 \%)$ had supraspinatus tendinitis, 2 (3.3\%) had bursitis, 2 (3.3\%) had periarthritis and the other 3 of the patients (5.1\%) were diagnosed with subscapularis tendinosis, bicipital tendinitis and dull shoulder diagnoses. Five (8.3\%)

Table II. Balance test results

\begin{tabular}{|c|c|c|c|c|c|c|c|c|c|c|}
\hline \multirow[t]{2}{*}{ Parameter } & \multicolumn{2}{|c|}{$\begin{array}{l}\text { VAS - at rest } \\
1^{\text {st }} \text { group }\end{array}$} & \multicolumn{2}{|c|}{$\begin{array}{l}\text { VAS - at rest } \\
2^{\text {nd }} \text { group }\end{array}$} & \multirow[t]{2}{*}{$P$-value } & \multicolumn{2}{|c|}{$\begin{array}{c}\text { VAS - dur. } \\
\text { mvnt } \\
1^{\text {st }} \text { group }\end{array}$} & \multicolumn{2}{|c|}{$\begin{array}{l}\text { VAS - dur. } \\
\text { mvnt } \\
2^{\text {nd }} \text { group }\end{array}$} & \multirow[t]{2}{*}{$P$-value } \\
\hline & $\bar{x}$ & SD & $\bar{x}$ & SD & & $\bar{x}$ & SD & $\bar{x}$ & SD & \\
\hline BBS & 55.23 & 0.74 & 54.71 & 1.10 & 0.08 & 55.05 & 0.97 & 55.04 & 0.89 & 0.95 \\
\hline FES & 92.58 & 7.21 & 89.23 & 9.24 & 0.22 & 93.47 & 7.26 & 90.46 & 8.32 & 0.13 \\
\hline \multicolumn{11}{|l|}{ SPORTKAT System: } \\
\hline Double-foot static balance & 325.12 & 100.93 & 351.55 & 93.45 & 0.22 & 335.58 & 78.35 & 333.81 & 107.32 & 0.71 \\
\hline Double-foot left score & & & & & 0.53 & & & & & 0.32 \\
\hline Double-foot right score & & & & & 0.33 & & & & & 0.86 \\
\hline Double-foot Static RL ratio & & & & & 0.10 & & & & & 0.11 \\
\hline Double-foot front score & & & & & 0.15 & & & & & 0.52 \\
\hline Double-foot back score & & & & & 0.73 & & & & & 0.72 \\
\hline Double-foot Static FB ratio & & & & & 0.29 & & & & & 0.36 \\
\hline $\begin{array}{l}\text { Single-foot (Right) Static } \\
\text { Balance }\end{array}$ & 447.25 & 219.63 & 386.82 & 97.54 & 0.46 & 510.18 & 268.28 & 387.14 & 120.53 & 0.07 \\
\hline Single-foot (Right) Left Score & & & & & $0.02^{*}$ & & & & & 0.13 \\
\hline Single-foot (Right) Right Score & & & & & 0.77 & & & & & 0.76 \\
\hline Single-foot (Right) RL ratio & & & & & $0.02^{*}$ & & & & & 0.47 \\
\hline Single-foot (Right) Front Score & & & & & 0.65 & & & & & 0.57 \\
\hline Single-foot (Right) Back Score & & & & & 0.60 & & & & & 0.40 \\
\hline Single-foot (Right) FB ratio & & & & & 0.98 & & & & & 0.64 \\
\hline Single-foot (Left) Static Balance & 408.26 & 165.79 & 395.84 & 174.29 & 0.85 & 431.35 & 148.75 & 391.20 & 175.70 & 0.34 \\
\hline Single-foot (Left) Left Score & & & & & 0.67 & & & & & 0.51 \\
\hline Single-foot (Left) Right Score & & & & & 0.67 & & & & & 0.79 \\
\hline Single-foot (Left) RL ratio & & & & & 0.95 & & & & & 0.10 \\
\hline Single-foot (Left) Front Score & & & & & 0.40 & & & & & 0.23 \\
\hline Single-foot (Left) Back Score & & & & & 0.25 & & & & & 0.58 \\
\hline Single-foot (Left) FB ratio & & & & & 0.48 & & & & & 0.34 \\
\hline Dynamic Balance & 2269.74 & 355.88 & 2278.49 & 333.81 & 0.92 & 2323.21 & 332.31 & 2249.44 & 352.99 & 0.44 \\
\hline Dynamic Left Score & & & & & 0.70 & & & & & 0.47 \\
\hline Dynamic Right Score & & & & & 0.68 & & & & & 0.12 \\
\hline Dynamic RL Ratio & & & & & 0.98 & & & & & 0.97 \\
\hline Dynamic Front Score & & & & & 0.41 & & & & & 0.44 \\
\hline Dynamic Back Score & & & & & 0.72 & & & & & 0.72 \\
\hline Dynamic FB Ratio & & & & & 0.64 & & & & & 0.51 \\
\hline
\end{tabular}

VAS - at rest - Visual Pain Scale - at rest, VAS - dur. mvnt - Visual Pain Scale - during movement, BBS - Berg Balance Scale, FES - Fall Efficacy Scale, RL - Right-Left, FB - Front-Back. 
Table III. Relationship between VAS - at rest, VAS - dur. mvnt and Sportkat results

\begin{tabular}{|c|c|c|c|c|}
\hline \multirow[t]{2}{*}{ Parameter } & \multicolumn{2}{|c|}{ VAS-at rest } & \multicolumn{2}{|c|}{ VAS-during movement } \\
\hline & $r$ & $P$-value & $r$ & $P$-value \\
\hline \multicolumn{5}{|c|}{ Double Foot Static: } \\
\hline Score & 0.152 & 0.247 & 0.038 & 0.776 \\
\hline RL & 0.271 & $0.036^{*}$ & 0.228 & 0.080 \\
\hline $\mathrm{FB}$ & -0.021 & 0.875 & -0.159 & 0.224 \\
\hline \multicolumn{5}{|c|}{ Single Foot (Right) Static: } \\
\hline Score & -0.050 & 0.706 & -0.092 & 0.483 \\
\hline$R L$ & 0.238 & 0.068 & -0.056 & 0.671 \\
\hline $\mathrm{FB}$ & 0.134 & 0.309 & 0.089 & 0.498 \\
\hline \multicolumn{5}{|c|}{ Single Foot (Left) Static: } \\
\hline Score & 0.056 & 0.672 & -0.007 & 0.958 \\
\hline RL & -0.025 & 0.849 & -0.019 & 0.887 \\
\hline $\mathrm{FB}$ & 0.093 & 0.477 & -0.021 & 0.873 \\
\hline \multicolumn{5}{|l|}{ Dynamic: } \\
\hline Score & 0.064 & 0.627 & -0.049 & 0.712 \\
\hline RL & 0.063 & 0.631 & 0.098 & 0.456 \\
\hline$F B$ & -0.49 & 0.711 & 0.153 & 0.244 \\
\hline
\end{tabular}

${ }^{*} p<0.05$, VAS - Visual Pain Scale, RL - Right-Left, FB - Front-Back.

of the participants were housewives, 4 (6.7\%) were teachers, $9(15 \%)$ were in the health sector, 9 (15\%) were labourer, 4 (6.7 \%) were military employees, 1 (1.7\%) were retired and 28 (46.7\%) were employed in desk work. While 7 of the participants were not working, 53 were working. Ten (16.7\%) of the participants had a history of falling within 1 year.

The $t$-test results are shown in Table II. Intergroup comparisons showed a statistically significant difference between the single foot (right) static balance left score and the single foot (right) static balance RL ratio with the Sportkat System

Table IV. Relationship between VAS-at rest and VAS-during movement and Balance and Fall Risk/ Fear of Falling tests

\begin{tabular}{|lcc|}
\hline & $\begin{array}{c}\text { VAS } \\
\text { at rest }\end{array}$ & $\begin{array}{c}\text { VAS } \\
\text { dur. mvnt }\end{array}$ \\
\hline BBS & & \\
\hline$r$ & -0.311 & -0.053 \\
\hline$P$-value & $0.016^{*}$ & 0.687 \\
\hline FES & & \\
\hline$r$ & -0.237 & -0.244 \\
\hline$P$-value & 0.068 & 0.060 \\
\hline
\end{tabular}

${ }^{\star} P<0.05$, VAS - Visual Pain Scale, BBS - Berg Balance Scale, FES - Fall Efficacy Scale. for the VAS-rest subgroups ( $p<0.05)$. There was no statistically significant difference between the groups in terms of all variables for VAS-at movement results $(p>0.05)$.

A statistically weak positive but significant correlation was found between right and left (RL) ratio of the patients between the resting-balance and equilibrium static balance test $(p<0.05)(\mathrm{Ta}-$ ble III). No statistically significant relationship was found between the other parameters $(p>0.05)$.

There was a negative weak but statistically significant relationship between VAS-at rest and BBS $(p<0.05)$ (Table IV). There was no statistically significant relationship between VAS-rest and VAS-activity and other tests $(p<0.05)$.

\section{Discussion}

Shoulder problems are more common in the working population and the risk of experiencing shoulder problems increases with the addition of physical workplace factors such as work involving overhead activities, weight lifting, work requiring strength, as well as working in the wrong posture $[2,26]$. In parallel with the literature, the majority of participants were in the working group, but the majority of the group consisted of individuals working in desk work. We think that causes of shoulder pain may be working in the wrong posture, repet- 
itive activities or psychological risk factors in the workplace. Female gender, obesity, smoking and high age are non-occupational personal risk factors that cause shoulder problems [2, 26, 27]. The majority of the participants were female and overweight, in parallel with the literature [1, 2, 26].

In studies conducted on diseases that cause widespread chronic pain such as low back pain, knee osteoarthritis, and fibromyalgia, it has been observed that as the severity of pain increases, the balance ability deteriorates, postural stability oscillations increase, and risk of falling and fear of falling increase [9, 11-13, 28, 29]. Patients with respiratory problems $[20,21]$ and patients with foot problems [30] have also been shown to have increased fall risk. However, the number of studies looking at this relationship was limited in shoulder pain. Therefore, in our study, the relationship between pain severity and balance, postural stability and fall risk was investigated in shoulder pathologies.

Baierle et al. compared patients with moderate to severe shoulder pain and healthy individuals with pathology causing shoulder pain in terms of balance and postural stability ability [5]. It was found that balance ability and postural stability of individuals with moderate and severe shoulder pain were adversely affected compared to the healthy group. However, no relationship was found between pain severity and balance ability and postural stability. In this study, balance ability and postural stability were evaluated with the S3-Check system (MFT - Grosshoeflein, Germany) and pain severity was evaluated with the 15-point VAS. Also, unlike our study, only patients with moderate and severe shoulder pain were included in the study and these individuals were not compared among themselves and individuals were not evaluated for fall risk and fear of falling.

The findings of our study show that dynamic balance ability was affected. According to the Sportkat System measurement scores, the result of the 1950 index score and above is interpreted as not good [31]. The average of our participants was calculated as an index score 2269.74. However, in our study, when we look at the relationship between pain severity at rest and activity, balance ability measured by the Sportkat System, postural stability and fall risk, no statistically significant relationship was found between pain severity and dynamic balance scores assessed by the Sportkat System. As Khalaj et al. explained in their study in 2014, loss of balance occurs mostly in movement-related functions such as walking, and less in static activities [9]; we think our results showed the same pattern [32].

When pain groups were compared, it was found that postural oscillations of the individuals increased to the left in the posture on the right foot.
Parallel to this, as the pain severity at rest increases, the oscillations in the medio-lateral direction increase in the one-foot posture on the right foot. We think that the physiotherapy approaches of the patients with shoulder pain that we will include in the physiotherapy program should include physiotherapy approaches not only for the pain but also for the increased postural oscillations.

In our study, it was observed that balance ability and fall risk were negatively affected as the pain severity increased. While there was no correlation between the pain severity in movement and the balance ability, postural stability and fall risk in both measurements made with the Sportkat System and the measurements performed with BBS, it was found that the pain severity in BBS increased as the severity of pain fell at rest and the balance in the Sportkat System was not improved. Postural stability may be affected by the severity of pain. According to our findings, as the severity of pain at rest increases, postural oscillations in the medio-lateral direction increase in double foot posture. We think that the Sportkat System examines the balance ability, postural stability and fall risk in more detail and that BBS examines the functional balance ability, because, when we look at the mean scores of the two instruments, a relationship was found when we correlated with the severity of pain while the balance ability was not affected.

A recent population-based study [33] stated the importance of understanding the causes and consequences of pain. In the light of our study findings, further research is necessary to evaluate the effect of shoulder pain on balance parameters. A bigger sample of patients and grouping the patients according to diagnosis at all levels of pain severity would be beneficial to improve the strength of the research. Duration of pain has not been limited for a specific period for the sample. As postural input might have been affected by duration of pain, this parameter would have been limited, which would help to better identify the relationship. Also, the methods of treatment received since the pathology have not been recorded, which could also influence the parameters of the study. These limitations should be addressed in future studies.

In conclusion, shoulder pain affects balance ability and postural stability of the individuals and increases the risk of falling. Therefore, the addition of balance and postural control approaches to the rehabilitation programs of people with shoulder pathology is suggested to protect this population against falling.

\section{Conflict of interest}

The authors declare no conflict of interest. 


\section{References}

1. Chester R, Shepstone L, Daniell H, Sweeting D, Lewis J, Jerosch-Herold C. Predicting response to physiotherapy treatment for musculoskeletal shoulder pain: a systematic review. BMC Musculoskelet Disord 2013; 14: 203-19.

2. Luque-Suarez A, Rondon-Ramos A, Fernandez-Sanchez M, Roach KE, Morales-Asencio JM. Spanish version of SPADI (shoulder pain and disability index) in musculoskeletal shoulder pain: a new 10-items version after confirmatory factor analysis. Health Qual Life Outcomes 2016; 14: 32-40.

3. Treede RD, Apkarian AV, Bromm B, Greenspan JD, Lenz FA. Cortical representation of pain: functional characterization of nociceptive areas near the lateral sulcus. Pain 2000; 87: 113-9.

4. Myers JB, Lephart SM. Sensorimotor deficits contributing to glenohumeral instability. Clin Orthop Relat Res 2002; 400: 98-104.

5. Baierle T, Kromer T, Petermann C, Magosch P, Luomajoki $\mathrm{H}$. Balance ability and postural stability among patients with painful shoulder disorders and healthy controls. BMC Musculoskelet Disord 2013; 14: 282-91.

6. Sciascia A, Cromwell R. Kinetic chain rehabilitation: a theoretical framework. Rehabil Res Pract 2012; 2012: 853037.

7. Hansen M, Dieckmann B, Jensen K, Jakobsen B. The reliability of balance tests performed on the kinesthetic ability trainer (KAT 2000). Knee Surg Sports Traumatol Arthrosc 2000; 8: 180-5.

8. Horlings CG, Van Engelen BG, Allum JH, Bloem BR A weak balance: the contribution of muscle weakness to postural instability and falls. Nat Rev Neurol 2008; 4: 504-15.

9. Khalaj N, Osman NAA, Mokhtar AH, Mehdikhani M, Abas WABW. Balance and risk of fall in individuals with bilateral mild and moderate knee osteoarthritis. PLoS One 2014; 9: e92270.

10. Paillard T, Noé F. Techniques and methods for testing the postural function in healthy and pathological subjects. Biomed Res Int 2015; 2015: 891390.

11. Ruhe A, Fejer R, Walker B. Pain relief is associated with decreasing postural sway in patients with non-specific low back pain. BMC Musculoskelet Disord 2012; 13: 39.

12. Ruhe A, Fejer R, Walker B. Is there a relationship between pain severity and postural sway in patients with non-specific low back pain? BMC Musculoskelet Disord 2011; 12: 162-70.

13. Lihavainen K, Sipilä S, Rantanen T, Sihvonen S, Sulkava R, Hartikainen S. Contribution of musculoskeletal pain to postural balance in community-dwelling people aged 75 years and older. J Gerontol A Biol Sci Med Sci 2010; 65: 990-6.

14. Howcroft J, Kofman J, Lemaire ED. Review of fall risk assessment in geriatric populations using inertial sensors. J Neuroeng Rehabil 2013; 10: 91-103.

15. Patel KV, Phelan EA, Leveille SG, et al. High prevalence of falls, fear of falling, and impaired balance in older adults with pain in the United States: findings from the 2011 National Health and Aging Trends Study. J Am Geriatr Soc 2014; 62: 1844-52.

16. Stubbs B, Schofield P, Patchay S. Mobility limitations and fall-related factors contribute to the reduced health-related quality of life in older adults with chronic musculoskeletal pain. Pain Pract 2016; 16: 80-9.

17. Belgen B, Beninato M, Sullivan PE, Narielwalla K. The association of balance capacity and falls self-efficacy with a history of falling in community-dwelling people with chronic stroke. Arch Phys Med Rehabil 2006; 87: 554-61.

18. Navarro-Flores E, Pérez-Ros P, Martínez-Arnau FM, Julían-Rochina I, Cauli O. Neuro-psychiatric alterations in patients with diabetic foot syndrome. CNS Neurol Disord Drug Targets 2019; 18: 598-608.

19. Leveille SG, Bean J, Bandeen-Roche K, Jones R, Hochberg M, Guralnik JM. Musculoskeletal pain and risk for falls in older disabled women living in the community. J Am Geriatr Soc 2002; 50: 671-8.

20. Calvo-Lobo C, Painceira-Villar R, García-Paz V, et al. Falls rate increase and foot dorsal flexion limitations are exhibited in patients who suffer from asthma: a novel case-control study. Int J Med Sci 2019; 16: 607-13.

21. Calvo-Lobo C, Painceira-Villar R, López-López D, et al. Tarsal tunnel mechanosensitivity is increased in patients with asthma: a case-control study. J Clin Med 2018; 7: 541-52.

22. Clark P, Lavielle P, Martínez $\mathrm{H}$. Learning from pain scales: patient perspective. J Rheumatol 2003; 30: 1584-8.

23. Alonso AC, Luna NM, Dionísio FN, Speciali DS, Leme LEG, Greve JMDA. Functional balance assessment. Medicalexpress 2014; 1: 298-301.

24. Şahin F, Büyükavcı R, Sağ S, Doğu B, Kuran B. Berg Denge Ölçeği'nin Türkçe Versiyonunun İnmeli Hastalarda Geçerlilik ve Güvenilirliği. Turk J Phys Med Rehab 2013; 59: 170-5.

25. Ulus Y, Durmus D, Akyol Y, et al. Reliability and validity of the Turkish version of the Falls Efficacy Scale International (FES-I) in community-dwelling older persons. Arch Gerontol Geriatr 2012; 54: 429-33.

26. Linaker $\mathrm{CH}$, Walker-Bone $\mathrm{K}$. Shoulder disorders and occupation. Best Practice Research Clin Rheumatol 2015; 29: 405-23.

27. Beach J, Senthilselvan A, Cherry N. Factors affecting work-related shoulder pain. Occup Med 2012; 62: 451-4.

28. Brognara L, Navarro-Flores E, lachemet L, Serra-Catalá N, Cauli O. Beneficial effect of foot plantar stimulation in gait parameters in individuals with Parkinson's disease. Brain Sci 2020; 10: 69-81.

29. Rodríguez-Sanz D, Tovaruela-Carrión N, López-López D, et al. Foot disorders in the elderly: a mini-review. Dis Mon 2018; 64: 64-91.

30. López-López D, Becerro-de-Bengoa-Vallejo R, Losa-lglesias ME, et al. Evaluation of foot health related quality of life in individuals with foot problems by gender: a cross-sectional comparative analysis study. BMJ Open 2018; 8: e023980.

31. Luberski T, Samango L. System and method of balance training. Google Patents 2007.

32. Navarro-Flores E, Cauli O. Quality of life in individuals with diabetic foot syndrome. Endocr Metab Immune Disord Drug Targets. 2020; doi: 10.2174/18715303206 66200128154036.

33. Huang YL, Tsay WI, Her SH, et al. Chronic pain and use of analgesics in the elderly: a nationwide population-based study. Arch Med Sci 2020; DOI: https://doi. org/10.5114/aoms.2020.92894. 